\title{
La Biblioteca de la Cámara Oficial de Comercio, Industria y Navegación de Melilla
}

\author{
Salvador Gallego Aranda
}

"Las Cámaras deberán invertir los sobrantes de la liquidación de los presupuestos en obras o servicios que redunden en beneficio colectivo de los elementos cuyos intereses representen, especialmente en la formación de estadísticas en relación con sus fines, en publicaciones y enseñanzas mercantiles, industriales y naúticas; en la formación de bibliotecas especializadas, servicios o museos comerciales o en otras actividades culturales $y$ económicas inherentes a dichos fines, o en la construcción de edificios para domicilio social o para la instalación de sus servicios de interés general. "(Reglamento Interior, 1930, art. 77, p. 34 y 35).

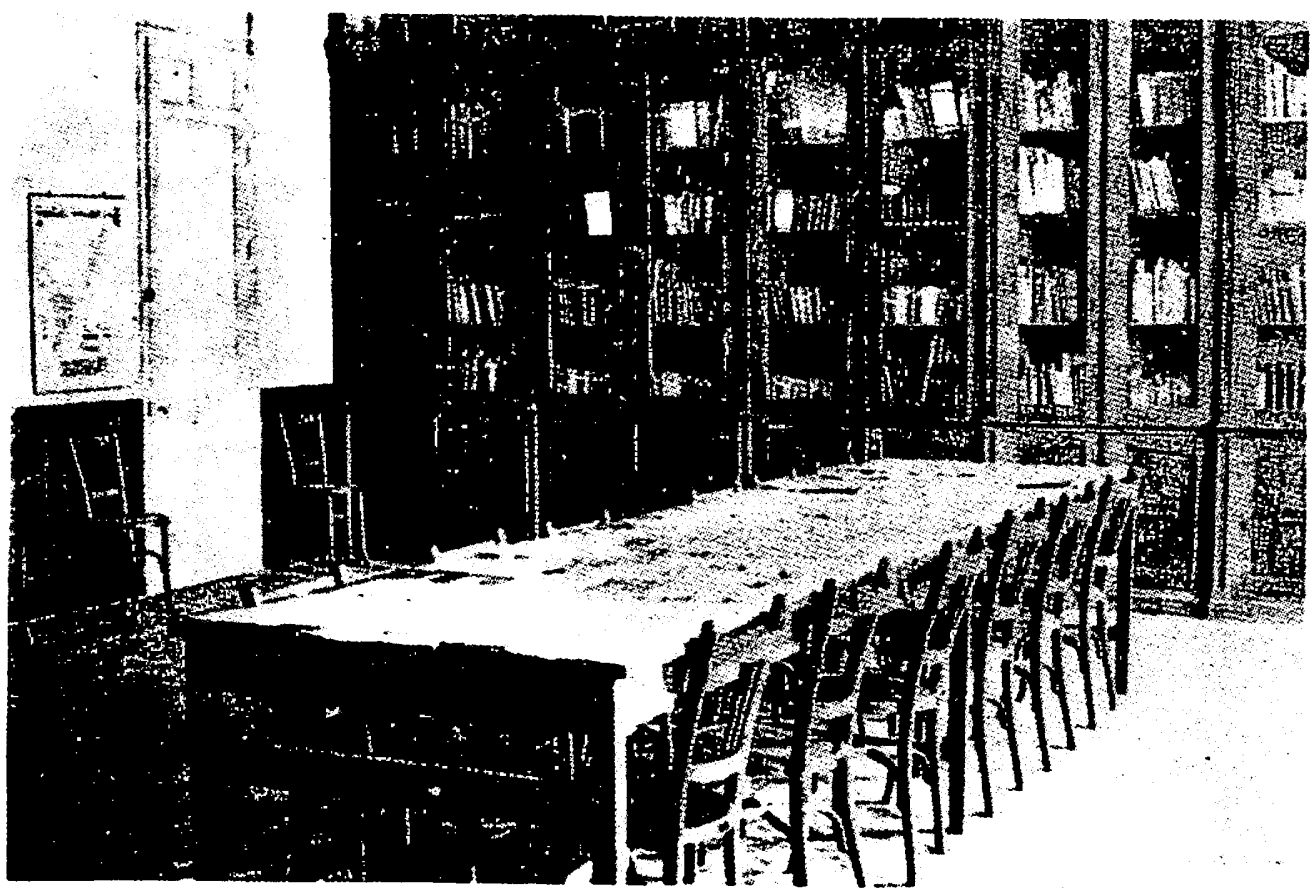

Biblioteca de la Cámara de Comercio (ubicación y disposición en 1915, año de la inauguración del edificio). (Archivo fotográfico del autor). 


\section{Biblioteca}

"La de la Cámara estará abierta para el público durante el presente mes todos los días, excepto los festivos, de 3 a 5 de la tarde". (Enero de 1911).

Rastrear los origenes de una idea es prácticamente imposible y más aun cuando ésta es fruto de un campo abonado donde se irán dando cita multitud de semillas a cual de ellas más fecunda. Por ello es realmente muy difícil seguir la evolución de una, sin ver, paralelamente, èl desarrollo de las otras.

Hablar de la Biblioteca de la Cámara lleva consigo analizar una serie de cuestiones paralelas que complementan la labor que lleva a cabo este Corporación, pues, ni la creación del Museo Comercial -idea original que desembocaría en la construcción de la sede social—, ni la de las Clases Comerciales y otras actividades que posteriormente veremos, se pueden deslindar de la puesta en funcionamiento de unos fondos bibliográficos públicos que, aunque no reconocidos previamente como tales, estaban al alcance de todos sin distinción de profesiones y, mucho menos, de razas.

Desde la "Asociación Mercantil e Industrial de Propietarios", organismo precedente de la Cámara - 16 de octubre de 1906 - fue tomando forma el citado proyecto; las primeras noticias que tenemos nos remiten al 7 de enero de 1907 en cuya sesión se solicitan obras para la Biblioteca. Un mes después 12 de febrero de 1907-: "Se dio cuenta -en dicha sesion- de haber pasado circulares a todos los escritores espanfoles pidiendo libros para la biblioteca..."

Es de señalar, dentro de este punto, el valor que tendrán las donaciones en la adquisición de libros. Serfa muy extensa la lista de obras, personas y organismos que contribuyeron con su aportación a enriquecer cualitativamente, a la vez que de forma cuantitativa, los fondos documentales de la Cámara, si bien sería un error por nuestra parte no reiterar el agradecimiento y la gran misión que sus aportaciones lograron desempenar. El destacar aqur algunas de ellas será desde un punto de vista meramente referencial, pues tan valiosas han sido éstas como las otras.

De tal suerte la Cámara será receptora de un:

- "Valioso donativo: 'El Senado ha regalado a esta Cámara de Comercio 54 obras con destino a su Biblioteca".'.

- "Oficio del Iltmo. Sr. Subsecretario del Ministerio de Instrucción Pública enviando a la Cámara varias importantes obras..."2

Abreviaturas utilizadas en las notas a pié de página: B.C.: Boletín de la Cámara de Comercio, Industria y Navegación de Melilla; L.A.: Libro de Actas de la Cámara oficial de Comercio...; M.T.: Memoria de trabajos de la Cámara de Comercio...

1. B. C. AÑo IV, Núm. 15, 15-marzo-1909, p. 7.

2. B. C. AÑo V. Núm. 36, 1-marzo-1910, p. 1. 
- “... carta del Excmo. Sr. D. Francisco Lastres, senador vitalicio, enviando.. ejemplares de su obra Libro de la familia". ${ }^{3}$

- "Carta del Excmo. Sr. Marqués de Villasinda, Ministro de España en Tánger, enviando a la Cámara,... ejemplares de varias obras de las que es autor". ${ }^{4}$

- "Carta del Excmo. Sr. Obispo de Jesea remitiendo un donativo de libros...".s

-“... libros concedidos por el Instituto Geográfico y Estadístico y Dirección General de Obras Públicas".6

- “... del E. S. D. Antonio Maura, remitiendo ejemplares de discursos que han tenido edición especial"?

-Donativos también por parte del Ayuntamiento, ${ }^{8}$ Cámara de Comercio ${ }^{9}$ y Federación de la Propiedad de Barcelona, ${ }^{10}$ Ayuntamiento de Madrid, ${ }^{11}$ Real Academia de Ciencias Morales y Políticas, ${ }^{12}$ Ministerio de Instrucción Pública, ${ }^{13}$ Real Academia de la Historia, ${ }^{14}$ etc.

- Sociedades privadas, Corporaciones Oficiales y Ministerios responden al llamamiento de la Cámara e inclusive se recurre"... a los Sres. Socios de la Cámara para que regalen obras con destino a la Biblioteca". ${ }^{15}$

Junto a las donaciones, la Cámara, por su parte, adquiere también un buen número de obras como son:

- "... de la Biblioteca Soler de Barcelona, correspondientes a los números del 53 al 92 ambos inclusives". 16

- "Carta de D. Saturnino Calleja proponiendo el modo de adquirir 45 tomos de la Biblioteca de derecho". ${ }^{17}$

- "Carta del Director del Instituto Bibliográfico Africanista interesando que la Cámara se suscriba a sus obras".18

3. B. C. AÑo VI, Núm. 57, 15-enero-1911, p. 4.

4. B. C. AÑo VI, Núm. 62, 1-abril-1911, p. 1.

5. L. A. Tomo II Sesión 28-nov-1914, p. 423.

6. L. A. Tomo III Sesion 24-julio-1916, p. 57.

7. L. A. Tomo III Sesión 2-marzo-1917, p. 127.

8. B. C. AÑo VI Núm. 76, 15-diciem.-1911, p. 4. L. A. Tomo III Sesión 19-junio-1917, p. 176.

9. L. A. Tomo II Sesion 6-oct-1913, p. 286.

10. L. A. Tomo II Sesión 15-jun-1914, p. 371.

11. B. C. AÑo VI Núm. 89, 15-nov-1912, p. 2.

12. L. A. Tomo III p. 189.

13. B. C. ANO, VII Núm. 99, 1-sep-1913, pp. 2 y 5.

14. L. A. Tomo III Sesión 31-enero-1919 p. 494.

15. L. A. Tomo II Sesión 1-sep-1914, p. 396. L. A. Tomo III Sesión 21-feb-1917, p. 114.

16. B. C. AÑo VI Núm. 57, 15-enero-1991 p. 4.

17. L. A. Tomo III Sesión 1-agosto-1916, pág. 61.

18. L. A. Tomo III Sesión 2-marzo-1917, p. 127. 
- “Adquirir dos ejemplares de la obra Melilla Rifeñerías de que es autor D. Francisco Carcaño, ...". ${ }^{19}$

Entre las batallas que tiene que librar destacar el que:

- "Se incluya a la Cámara de Comercio entre las que reciben libros en los repartos de obras adquiridas por el Estado...".20

Con motivo del reparto de libros llevado a cabo por el Ministerio de Instrucción Pública ${ }^{21}$ se da la circunstancia paradojica de no encontrarse la de la Cámara incluida entre las Bibliotecas Públicas cuando realmente venía actuando como tal, al no existir en esta ciudad ninguna por parte del Estado, sólo la de sociedades, poco provista de libros y de uso exclusivo para los socios, como era el caso del Casino Militar. ${ }^{22}$

Los fondos en volúmenes pasan por las siguientes fechas:

-1 de mayo de 1909 (AÑ̃ IV Núm. 18 p. 2).............................900.

-15 de abril de 1910 (AÑO V Núm. 39 p. 2 y 3) ....................1.000.

-15 de abril de 1913 (AÑo VII Núm. 94 p. 5) .......................1.300.

-1 de enero de 1916 (AÑO X Núm. 125 p. 6) .........................1.500.

-1 de agosto de 1917 (AÑO XI Núm. 144 p. 7) ..........................800.

-1 de noviembre de 1918 (AÑO XIII Núm. 154 p. 4) ...........2.000.

Sefhalar, por último, que la mayorfa de las publicaciones recibidas por la Cámara, libros, revistas y periódicos, sea cual sea su procedencia, constan en los "Boletines" que ésta publica. (Anexo 1).

\section{Archivero-Bibliotecario}

La figura del archivero-bibliotecario queda reflejada en el Reglamento Interior de la Cámara de Comercio. Industria y Navegación de Melilla —aprobado el 24 de mayo de 1908 - de la siguiente forma: "Elegir los socios que han de desempeñar los cargos de Presidente, Vicepresidente, Tesorero, Contador, Archivero-Bibliotecario, y Secretario General" (Art. 17. 2) ${ }^{23}$ como parte de la Junta Directiva y como responsabilidad"... tendrá a su cargo la adquisición, previa consulta a la Directiva, de las obras destinadas a la Biblioteca, catalogándolas, y propondrá las publicaciones a que deba suscribirse la Corporación. Custodiará dentro del local de la Cámara todos los libros y documentos, y no permitirá por ningún concepto, que salgan éstos del propio local, a no mediar acuerdo de la Directiva". (Título Quinto Art. 47). ${ }^{24}$

19. L. A. Tomo IV Sesión 6-abril-1920, p. 51.

20. B. C. AÑO, VI Núm. 78, 15-febrero-1912, p. 4.

21. B. C. AÑo XI Núm. 138, 1-feb-1917, p. 6.

22. L. A. Tomo III Sesión 2-octubre-1916, p. 76.

23. B. C. AN̂O IX Núm. 121, 1-sept-1915, p. 8.

24. AÑ IX Núm. 122, 1-oct-1915, p. 7 y 8. 
-El 7 de enero de 1910 se produce la dimisión del Sr. Muñoz Leiva, primer Archivero-Bibliotecario de la Cámara, siendo el 17 del mismo mes D. Juan Barciela elegido para dicho cargo. ${ }^{25}$ Posteriormente lo sustituirá D. José Maŕa Zubizarreta ${ }^{26}$ y finalmente, resultando vacante el cargo de Bibliotecario que venía ejerciendo el Sr. Zubizarreta hasta el momento de ser elegido para Secretario es nombrado por aclamación el Sr. Nieto para desempeñarlo". ${ }^{27}$ Este será reelegido el 15 -enero de $1916,{ }^{28}$ última vez que dicha función se cubra, pues el dra 14 de agosto de 1920 tiene lugar, a los efectos del artículo 42 del Reglamento Orgánico aprobado por Real Decreto de 14 de marzo de 1918, la sesión de reorganización de ésta Corporación Oficial que se lleva a cabo los dras 18 y 19 de mayo, desapareciendo la figura de Archivero-Bibliotecario como parte constitutiva de la Mesa, pasando D. Enrique Nieto Nieto a ser Vocal Cooperador y quedando la biblioteca a cargo del secretario y dentro de la Comisión de Administración (Art. 40, Capftulo IV, del Reglamento de Régimen Interior en abril de 1930).

La Biblioteca: servicios, subvenciones, incautación del edificio, situación y puesta al día de los fondos

Una de las principales preocupaciones desde que se fundó la Cámara era que, cuando sus recursos lo permitieran, tuviera su biblioteca el carácter de pública, pues al estar abierta dos horas al día, de cinco a siete, no respondía ni satisfacía el servicio que querra desempenar, al ser portadora en sus fondos bibliograficos de varios temas de interes, sobre todo en su sección de Estudios Marroquíes. ${ }^{29}$

En el capitulo de subvenciones consignar la solicitada el 4 de marzo de 1910 al Ministerio de Instrucción Pública para la biblioteca de la Cámara, ${ }^{30}$ con objeto de adquirir más obras y mayor número de libros de texto, a la vez que la primera petición tiene lugar en la sesión de 23 de marzo de 1910: "Pedir al Ministerio de Instrucción Pública una biblioteca para fomentar la de la Cámara ${ }^{31}$ del tipo $D$ del Real Decreto de abril del año próximo pasado. ${ }^{32}$ No se le concede la misma al no existir en ese Departamento Ministerial consignación alguna para Bibliotecas. ${ }^{33}$

El 4 de octubre de 1911 se solicita de nuevo al Excmo Sr. Ministro de

25. B. C. AÑo V Núm. 34, 1-feb-1910, p. 1.

26. L. A. Tomo II Sesión 1-enero-1912, p. 101.

27. B. C. AÑo VII Núm. 91, 15-enero-1913, p. 4).

28. L. A. Tomo II Sesión 14-15-enero-16, pág. 576.

29. B. C. AÑo IV Núm. 18, 1-mayo-1909, p. 2.

30. B. C. AÑo V Núm. 38, 1-abr-1910 pp. 1 y 2.

31. L. A. Tomo I Sesión 23-marzo-1916, p. 334.

32. 31-marzo-1910.

33. B. C. AÑo, X Núm. 39, 15-abril-1910 pág. 3 28-marzo-1910. 
Instrucción Pública le conceda una biblioteca pública para una población de 40.000 habitantes en una ciudad donde son inexistentes tanto ateneos como bibliotecas públicas, abogando por el artículo 18 del presupuesto vigente para que se apruebe una subvención para instalarla y sostenerla, brindando sus modestos servicios en los apartados de organización, dirección y administración. ${ }^{34}$ Esta petición será retirada posteriormente en años sucesivos, ${ }^{35}$ siendo, por fin, en la sesión de 28-octubre-1913 cuando se recibe un "B. L M. del Excmo. Sr. Ministro de instrucción Pública remitiendo ordenes por las que se concede a la Cámara una Biblioteca Popular". ${ }^{36}$

Visto el poco éxito que va obteniendo, la Corporación da un giro a su política de subvenciones y, en sucesivas peticiones, se apoyará en otras empresas que se complementen con la puesta al día de la Biblioteca: así destaca la inauguración del 1 de octubre de las clases comerciales nutridas, lógicamente, en los fondos bibliográficos ${ }^{37}$ o bien la importancia que tiene la difusión de la cultura en esta posesión espanola para la atracción de los indígenas a la causa nacional. ${ }^{38}$ Referencia asimismo a la construcción del edificio para Museo Comercial y Sede Social de la Cámara como posibilidad de ampliar la biblioteca que tendría cabida en el mismo. ${ }^{39}$ Escuelas para ninos indfgenas, ${ }^{40}$ Escuela de árabe, ${ }^{41}$ etc. Lo mismo sucederá a la inversa y la Biblioteca servirá de apoyo a los demás proyectos; ejemplo claro de ello lo tenemos en la "Carta del Subsecretario de Estado referente a las 12.000 pesetas para construcción del edificio destinado a Museo y Biblioteca", ${ }^{42}$ o bien como réplica a la creación de un Museo Comercial por parte de los Centros Comerciales Hispano-Marroquíes, cuya subvención superaba con creces la de la Cámara, a la vez que no proporcionaba servicios como el de Biblioteca, Museo Comercial y Clases Comerciales que si prestaba la Corporación. ${ }^{43}$

Se pedirá a la Junta Facultativa de Archivos, Bibliotecas y Museos que apoye la inclusión en los próximos presupuestos de la cantidad necesaria para establecer una Biblioteca Pública o subvencionar la de la actual, llamando también la atención del Sr. Ministro de Estado por si encontrase en sus presu-

34. B. C AÑO, VI Núm. 74, 1-nov-1911, pp. 3 y 4. B. C. AÑO VI Núm. 77, 20-enero-1912, p. 7

35. B. C. AÑo VI Núm. 83, 15-julio-1912, p. 5 B. C. AÑo VI Núm. 87, 15-octub-1912, p. 7

36. L. A. Tomo II Sesión 28-octub-1913, p. 291 L. A. Tomo II Sesión l-diciem-1913, p. 302.

37. B. C AÑo VI Núm. 86, 15-sept-1912, p. 4 L. A. Tomo II Sesión 25-abril-1914, p. 354

L. A. Tomo II Sesión 1-mayo-1915, p. 491.

38. B. C. AÑO III Núm. 7, Agosto-1908, p. 2.

39. B. C. AÑO VII Núm. 94, 15-abril-1913, p. 5.

40. B. C. AÑO VII Núm. 91, 15-ene-1913, p.

41. L. A. Tomo Il Sesión 22-marzo-1914, p. 338.

42. L. A Tomo Il Sesión 17-nov-1913 pp. 300, 301.

43. L. A Tomo II Sesión 15-diciemb-1913, p. 306. 
puestos, medios para fomentarla. ${ }^{44}$ La respuesta no se hace esperar: "Carta del Excmo. Sr. Ministro de Instrucción Pública, manifestando que para el presupuesto de 1914 se incluirá la subvención de 4.000 pesetas para la Biblioteca" y por primera vez se concede una, por valor de 1.500 pesetas, por parte del Ministerio de Estado invirtiéndolas, por ser la primera necesidad a cubrir, en la adquisición de estanterfas y mobiliario, los más económicos dentro del croquis que les sería proporcionado por los señores D. Enrique Nieto y D. José Zubizarreta. ${ }^{45}$ En tales condiciones “... procediéndose a la apertura de los pliegos presentados con las ofertas para la construcción del mobiliario destinado a la Biblioteca, que resultaron ser firmados por los Sres. ... Duch y Robeda con presupuesto de 1.390 ptas. siendo adjudicado el referido mobiliario a estos últimos Sres. dadas las condiciones ventajosas del precio dentro del gusto artístico demostrado en los croquis que acompañaba, perfectamente en armonía con el estilo general del Edificio haciendo constar que se elevará el Coste del presupuesto total de 1900 , construyendo de nuevo la mesa de lectura" ${ }^{46}$ completándose con la librería que está construyendo para la biblioteca D José Robeda por valor de 900 pesetas; ${ }^{47}$ todo tendrá cabida en el nuevo edificio en una sala expresamente construida para ello de unas dimensiones"... de 8,6 por 8 me$\operatorname{tros}{ }^{48}$ y quedando constancia de la ampliación de su funcionamiento en el siguiente aviso: "El Museo Comercial, la Biblioteca y la Secretaria de la Cámara, estarán abiertos todos los días laborales, de 10 a 12 de la mafiana y de 5 a 7 de la tarde". 49

Carta del 17-nov-1915 relativa a la petición de una subvención para atender de forma decorosa el funcionamiento de la biblioteca de la Cámara. ${ }^{50}$

Fundamentando lo anterior, la Cámara no dudará en agotar todo el abanico de posibilidades que puedan tener como fin la obtención de una ayuda suplementaria para la biblioteca, de ahr que sea curioso resaltar la siguiente cita con todo lo que ella conlleva:

"Pedimos asimismo, una subvención para la Biblioteca de la Cámara, en el mes de Julio, fundándonos en que si muy justamente se reconocía que revestra para el fomento de la cultura de Tánger, la dotación por el Estado de una Biblioteca popular, allf donde sólo hay una colonia de unos 8.000 espafioles, muy justo también era que se hiciese en Melilla a la Biblioteca de la Cámara, única que tiene el carácter de pública, en una ciudad que como la nuestra,

44. B. C. AÑo VII Núm. 98, 1-agos-1913), pp. 5 y 6 Carta de 10 de junio de 1913. L. A. Tomo II Sesión 24-octubre-1911, p. 92.

45. B. C. AÑo VII Núm. 101, 1-nov-1913, p. 9.

46. L. A. Tomo II Sesión 23-diciembre-1913, p. 310.

47. L. A. Tomo II Sesión 23-mayo-1914, p. 491.

48. Boletín Extraordianrio de 31-julio-1915, p. 25.

49. B. C. AÑo IX Núm. 123, 1-nov-1915, p. 13.

50. B. C. AÑo X Núm. 125, 1-enero-1916 p. 6 L. A. Tomo II Sesión 17-enero-1916, p. 578. 
cuenta con treinta y seis mil habitantes, y una población militar de 28.000 hombres". ${ }^{51}$ De la misma manera que echar mano de su Régimen Interior donde se especifica que la Corporación se nutre de las cuotas voluntarias de sus asociados al no existir en dicho reglamento la obligatoriedad de pago de sus hermanas peninsulares. ${ }^{52}$ Reseñar que una de la últimas subvenciones que se pide por parte de la Cámara con destino a su biblioteca se produce en el mes de marzo de $1918,{ }^{53}$ la cual es denegada, aunque prometiendo concederla para las Clases Comerciales. El salto en el tiempo se ha dado, la meta está conseguida y la biblioteca está ya funcionando; el horario felizmente se ha ampliado en dos horas más, siendo de 10 a 13 y de las 16 a las 19,54 a la vez que se instalan por la Junta Municipal unas lámparas eléctricas. ${ }^{55}$ Pero a pesar de todo ésto, la situación de España en el Norte de Africa no era la más idonea y los cambios de gobierno, guerra civil y Segunda Guerra Mundial iban a convulsionar la vida de la Cámara dentro de su natural desarrollo y funcionamiento, sobre todo a partir de: “... escrito n. 3535 del Excmo. Sr. Delegado en Melilla del Gobierno General de las Plazas de Soberanía, trasladando comunicación del Excmo. Sr. Gobernador General, en la que se manifiesta que, habiendo resuelto que el edificio propiedad del Estado que hoy ocupa la Cámara Oficial de Comercio, Industria y Navegación de Melilla, quede afecto a los servicios de aquel Gobierno General, en el plazo de un mes, a partir de día nueve del actual". Cosa que, lógicamente, afectará a la sección de Biblioteca, que se verá privada de un espacio natural y propicio para desempeñar su cometido y, aunque la Cámara haga saber: "... que habida cuenta de la cantidad de mobiliario, libros de la copiosa Biblioteca. Archivos, Museo Comercial etc., y la necesidad de no interrumpir nuestra ordinaria función, rogábamos se acordase un mayor plazo para desalojar el edificio, y poder buscar locales adecuados en que instalarnos,... «se prorrogase» "... a seis meses..., en razón a la necesidad de hacer en condiciones responsables... los traslados". ${ }^{66}$ No se le concederá dicha propuesta y si el "... edificio designado para instalación de la Cámara, el ... $\mathrm{n}^{2} 9$ de la Calle Prim....". 57 "...donde con carácter provisional se han instalado nuestras oficinas...". ${ }^{\text {sB }}$

Realmente no queda ahi la cuestión, al recibirse un "...oficio del Juzgado Especial de la Comisión de Inventario de Bienes de Melilla..., disponiendo que en el término de ocho días procedamos a desalojar «dichos» ...locales...". 59 "...

51. B. C. AÑO X Núm. 136, 1-dic-1916, p. 8.

52. M. T. de 1917, 10-julio p. 3 y 4.

53. L. A. Tomo II Sesión 2-marzo-1918, p. 338.

54. B. C. AÑo XVII Núm. 191, Oct-1930 p. 3.

55. L. A. Tomo IV Sesión 14-marzo-1928, p. 354.

56. L. A. Tomo VI Sesión 20-dic-1938, p. 269b a 271.

57. L. A. Tomo VI Sesion 14-enero-1939, p. 272 a 273.

58. L. A. Tomo VI Sesión 24-febrero-1939, p. 275 y 276.

59. L. A. Tomo VI Sesión 4-mayo-1939, p. 277. 
en cuyos bajos, que eran y son almacenes, nos vimos obligados a amontonar los elementos que constituian nuestro hermoso salon de Actos, el mejor que había en la Ciudad, Biblioteca Pública, -única que desde 1915 existfa con este carácter en Melilla y tuvimos por la urgencia, que trasladar en atados-...."60 $\mathrm{El}$ nuevo traslado se hara a"... la calle de Granada $\mathrm{n}^{2} 1$, "61 quedando instalada "... nuestra Biblioteca pública...". ${ }^{62}$ Entre tanto y refiriéndose al edificio en construcción que ha de levantarse sobre el llamado de Correos y Telégrafos, donde tendrán cabida, entre otras, las instalaciones de la Cámara, se llama la atención"... para evitar vuelva a repetirse el doloroso caso de vernos privados de nuestras grandes instalaciones, Biblioteca y Museo Comercial, el día en que puedan cambiar las actuales dignas autoridades, pues ha sido grande el calvario sufrido por esta Cámara viéndose obligada a hacer en un afoo dos mudanzas, con los trastomos propios de estas operaciones y daños en el material y mobiliario que había sido construido expresamente por la Cámara al tiempo que levantábamos nuestro edificio". ${ }^{63}$

Dato digno de mención es: exponer al Excmo. Sr. General D. Carlos Asensio-Alto Comisario de Espafia en Marruecos- “... las condiciones de cesión de nuestro edificio de la calle de Cervantes, en el que tenfamos instalado con nuestra Biblioteca, un importante Museo Comercial de productos españoles, convertido ahora en Garage y oficinas de la Delegación del Gobierno, y unas Clases Comerciales que son ahora Biblioteca Municipal, lo que representa que en lo por nosotros construido a fuerza de sinsabores y desvelos, existen otras dependencias similares, que no son las nuestras, hecho que mantiene vivo un justo sentimiento que fácilmente comprenderá su reconocida ecuanimidad y justicia". ${ }^{64}$ Se constata, entonces, la instalación de la Biblioteca del Ayuntamiento en los locales de la Cámara de Comercio.

Durante el periodo de tiempo que la Cámara y sus servicios están en la calle Granada $n^{0} 1$, deberá acomodar y mantener unas instalaciones para el cuidado de su mobiliario, quedando ası constancia"... de haberse notificado a D. José Chocrón administrador de la casa que provisionalmente ocupa nuestra corporación de ser necesario, según informe del arquitecto municipal, nuestro vocal cooperador D. Enrique Nieto, realizar algunas obras en la azotea de este edificio para evitar dafios a la Biblioteca y enseres de nuestra corporación". ${ }^{65}$

Será a finales de los affos cuarenta cuando se respire de nuevo la esperanza de la vuelta al antiguo inmueble propiedad de la Cámara, con la idea de poder

60. M. T. aก̃o 1939, p. 24 L. A. Tomo VI Sesión 15-nov-1939, p. 281.

61. L. A. Tomo VI Sesión 16-enero-1940, p. 292 b.

62. L. A. tomo VII Sesión 15-junio-1940, p. 11 y 12.

63. Año 1940, p. 15 y 16 L. A. Tomo VI Sesión 16-mar-1940, p. 298 b y 299.

64. M. T. año 1941, p. 36 Memoria Ayuntamiento Melilla año 1941, p. 150.

65. L. A. Tomo VII Sesión 19-feb-1946, p. 272. 
restituir los servicios que dicha Corporación venía realizando, en sus mejores condiciones, antes de la incautación del edificio. ${ }^{66}$ Este último tramo, aunque corto, se hacía ya desesperante: "A pesar de no haber cejado en nuestras gestiones tampoco pudo nuestra Cámara en el año 1950 reintegrarse, como esperábamos - luego de las reiteradas promesas que se nos hicieron-, a su edificio social sito en la calle Cervantes $n^{2} 7 .$. "... demora... «que» viene ocasionando a esta Cámara Oficial muy sensible perjuicios de orden administrativo, al no poder montar con la debida eficiencia nuestros servicios, abundantísimo Archivo, y Biblioteca de carácter público...".67 En noviembre de 1951 queda constancia de la devolución de la Sede Social al organismo corporativo, si bien las condiciones en que se encuentra el inmueble no son las más deseables para la rápida puesta en escena de la serie de ofertas - ya mencionadas- de las que era portadora la Cámara. La restauración y rehabilitación del edificio son tan necesarias que ocupan un puesto primordial en el orden de prioridades, siempre bajo la vigilante tutela de un presupuesto que, aunque desahogado, no tan boyante como para que se produzca el trasvase laborioso y de servicios que hubo en épocas anteriores. ${ }^{68}$

Por ello, reseñar por último que, aún “...volviendo a situar la Biblioteca donde estaba antiguamente"69 dentro del proyecto de rehabilitación del edificio ${ }^{70}$ - “... aprobado por la secretaría General Técnica del Ministerio de Comercio $^{71}$ — concluido a finales de $1956^{72}$ y junto a "... la reforma y decoración del salón de actos, biblioteca, despacho del Secretario, oficinas, y de los servicios..." terminadas antes de finalizar el affo $1978,{ }^{73}$ el servicio que ofrecra la sección bibliografica habia desaparecido, quedando los fondos amontonados e ilocalizados en una amalgama documental sólo visitada, de forma esporádica, por estudiosos que velan limitada su búsqueda a la intuición, siendo presa fácil de una desesperación a todas luces comprensiva.

Hoy por hoy, la biblioteca de la Cámara, como es l6gico, sigue contando con dichos fondos, aunque considerablemente mermados por el paso del tiempo, ya que algunos ejemplares han desaparecido y otros están inutilizables.

Sería árdua y pesada la tarea, que si necesaria, de ir comparando el actual registro con los anteriores - dos, uno de ellos ilocalizable - para poder cotejar realmente el número de pérdidas en este espacio de tiempo, a la vez que la disposición y ordenamiento que dichos fondos tenían dentro de la biblioteca.

66. M. T. aก̃o 1949 , p. 26.

67. M. T. año 1950 , p. 8.

68. L. A. Tomo VII Sesión del 30-nov-1951 p. 437.

69. L. A. Tomo VII Sesión 11-mayo-1954, pp. 547, 548.

70. L. A. Tomo VII Sesión 11-Jun- 1954, pp. 550 a 554.

71. L. A. Tomo VII Sesión 14-junio-1954, p. 579.

72. L. A. Tomo VII Sesión Enero-1957, pp. 21 y 22.

73. M. T. ลก็ก 1978 , p. 165 . 
El registro original lo tenemos ordenado alfabéticamente por materias, siendo portador de la mayoria de las obras existentes si bien aparecen en algunos libros los números de registro distintos, indicando la existencia de una clasificación posterior no encontrada. El número de libros ha aumentado relativamente con aquel de 1918 (2.000) al que hacíamos referencia. Actualmente consta, aproximadamente de 2.500 volúmenes, si bien esta cifra puede ampliarse por restos muy sectoriales aún sin catalogar y la adición pertinente de revistas, boletines y memorias relacionados con las actividades de la Corporación.

La importancia de la Biblioteca de la Cámara - lo que ha condicionado su puesta al día - viene dada por el papel primordial que desempeño este organismo -único civil- en una Melilla de principios de siglo, bajo las directrices de la Junta de Arbitrios. Por ello, algunas atribuciones tomadas en su momento por la Corporación pueden ser consideradas hoy en día ajenas a su natural función, asf como el relacionar los fondos de su biblioteca limitados a la especialización de las materias que les competen, y esto no es asf. Hemos visto como se resalta la sección de estudios africanistas entre las demás y como esa ambigüedad que oscila entre lo popular y lo público, diffcilmente definible, puede inducir a un error que no queremos. Los temas tratados abarcan campos como la Literatura, Geografra, Historia, Arte, Religión, etc. Y de forma ineludible, cuenta también con un amplio temario relacionado directamente con el epicentro y periferia de las actividades camerales. Por eso se puede encontrar de todo en una Biblioteca que era fiel reflejo de la vida de una ciudad en expansión y a la que hay que acudir si queremos conocer nuestro pasado más reciente. Eso antes no se podía hacer de forma completa, los fondos estaban amontonados, siendo los libros murallas de diff́cil acceso. Este obstáculo ha sido salvado por la presente Corporación, conocedora de la gran valía de sus documentos y de la imposibilidad de mantener durante más tiempo las vitrinas cerradas a cal y canto. No es esa su misión, sino la de abrir todos los caminos viables para el florecimiento de una ciudad comenzando por su pasado, rico en hechos y situaciones que actualmente se repiten; en Melilla no hay problemas nuevos sino los mismos problemas, la lucha no empieza ahora sino que continúa. Bastante rápido pasa el tiempo para detenernos a contemplar su velocidad intentando buscar nuevos caminos, éstos, como el caudal mayor o menor de un ró, buscan, por fin, que señalicemos su cauce.

ANEXO 1: BOLETfN DE LA CÁMARA DONDE SE RECOGEN LA PUBLICACIONES RECIBIDAS

$\begin{array}{lll}\text { AÑO VI: } & \text { Núm. } 76 & \text { 15-diciembre-1912, p. 4; } \\ & \text { Núm. } 85 & \text { 15-agosto-1912, p. 8; } \\ \text { Núm. } 87 & \text { 15-octubr-1912, p. } 7 \text { y } 8 . \\ & \text { Núm. } 89 & \text { 15-noviem-1912, p. 8. }\end{array}$




\begin{tabular}{|c|c|c|}
\hline AÑO VII & $\begin{array}{l}\text { Núm. } 98 \\
\text { Núm. } 101\end{array}$ & $\begin{array}{l}\text { 1-agosto-1913, p. } 10 \\
1 \text {-noviem-1913, p. } 9 .\end{array}$ \\
\hline AÑO VIII & Núm. 109 & 1 -septiem-1914, p. 7,8 y 10. \\
\hline AÑo IX & Núm. 114 & 1-enero-1915, p. 8 y 9; \\
\hline & Núm. 116 & 1-marzo-1915, p. 6 \\
\hline & Núm. 117 & 1-abril-1915, p. 6 \\
\hline & Núm. 118 & $1-$-mayo-1915, p. 7 y 8. \\
\hline & Núm. 119 & 1-junio-1915, p. 8; \\
\hline & Núm. 120 & 1-julio-1915, p. 9 ; \\
\hline & Núm. 121 & 1-sept-1915, p. 8 y 9. \\
\hline AÑo XIII & Núm. 161 & 1-enero-1919, p. 7 \\
\hline
\end{tabular}

